\title{
Delayed cord clamping in the compromised baby
}

\begin{abstract}
Compromised babies are routinely immediately separated from the umbilical cord in order to be resuscitated. The benefits of delayed cord clamping are numerous and apply as much, if not more, to the non-breathing baby, thus it is important to ask 'does early cord clamping cause harm?' The evidence suggests that early cord clamping can cause bradycardia in the baby and create the need for resuscitation. Invasive measures such as drugs and volume expanders are not required as frequently when delayed cord clamping is practised. Allowing the placenta to perform its role in the resuscitation means that oxygen supply continues, despite the failure to achieve effective respiration immediately. There appears to be no adverse psychological affects for the mother and birth partner if adequate midwifery support is provided. As midwives we must use the best available evidence to support our practice and improve outcomes.
\end{abstract}

Keywords: Delayed cord clamping, Compromised infant, Neonatal resuscitation, Placental transfusion, Neonatal transition

Felicity Gruneberg

Midwife

Queen Elizabeth Hospital

King's Lynn

Kenda Crozier

Senior Lecturer

University of East Anglia
W

hen a baby is born it begins its adaption to extra-uterine life. Delayed cord clamping is a normal part of gentle transition (Mercer and Erikson-Owens, 2010) and has been widely advocated as a means of preventing iron deficiency in babies (World Health Organization (WHO), 2012). Compromised babies are routinely separated from the umbilical cord immediately after birth, and rushed to a Resuscitaire, a more comfortable environment for the health practitioner, and the place deemed most appropriate by paediatricians. New guidance from the National Institute for Health and Care Excellence (NICE) (2014) recommends leaving the cord intact for at least 1 minute in active management, unless the baby has a heartbeat of less than 6o beats per minute that is not getting faster. It is estimated that $5-10 \%$ of newborns in the developed world require some form of resuscitation, although the majority of these only need stimulation, and just $1 \%$ require assisted ventilation (Castle, 2009). The logical action is to provide support to the baby by the perineum, ensuring the non-breathing child remains attached to its only source of oxygen (Mercer and EriksonOwens, 2010).

To answer the question 'does delayed cord clamping in the compromised baby confer benefits?' a literature review was conducted. Electronic searches were performed of the databases CINAHL, MEDLINE, Wiley Online Library, Cochrane Library and MAG Online Library. A further search of the reference lists in relevant articles was then performed by hand. The search terms used were 'delayed cord clamping' and 'placental transfusion' combined with 'neonatal resuscitation' and 'compromised baby'.

\section{Known benefits of delayed cord clamping}

Clamping and cutting the umbilical cord was introduced in the 17th century to reduce blood spilling onto the bedclothes (Johnson and Taylor, 2011) and has remained common practice to this day with no medical indication. The wisdom of this has been challenged for centuries, with Erasmus Darwin in 1801 stating that the cord should be left untouched until after the child has repeatedly breathed and pulsation has ceased.

Early cord clamping is usually defined as clamping within 30 seconds of birth and delayed cord clamping after 2-5 minutes, or when pulsation ceases, although definitions vary (Airey et al, 2008). Delaying the clamping of the umbilical cord for more than 2 minutes has been proven to be beneficial to the newborn (Hutton and Hassan, 2007). The value of delayed cord clamping is now widely recognised and recommended (Royal College of Midwives (RCM), 2012; WHO, 2012). The cardiovascular, pulmonary, central nervous, haematological and integumentary systems all benefit from placental transfusion (Niermeyer and Velaphi, 2013).

Delayed cord clamping is associated with higher haemoglobin levels for up to 4 months, and higher ferritin levels for 6 months following birth (McDonald and Middleton, 2008). Iron deficiency is the most common nutrient deficiency worldwide (Hutton and Hassan, 2007) and thus this simple and low-cost action may be an efficient preventive factor for babies (Mercer and Erikson-Owens, 2010). Anaemia can cause harm to the brain as it develops (Lozoff et al, 2006) and may cause lasting cognitive impairment with behavioural problems seen into adolescence (Lozoff and Georgieff, 2006). The reduced incidence of anaemia resulting from delayed cord clamping improves the baby's resistance to infection (Weckert and Hancock, 


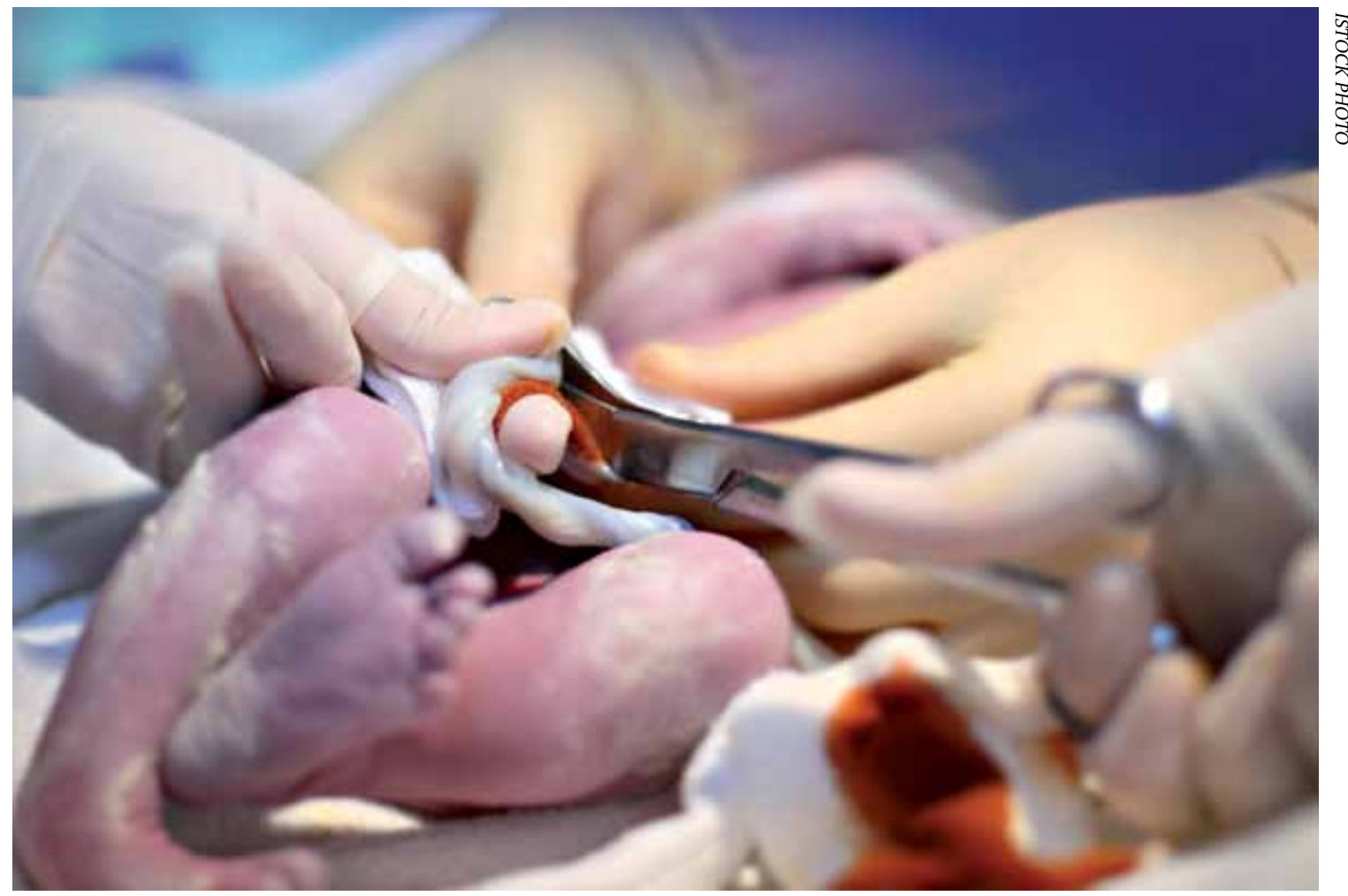

2008). Evidence suggests that iron availability in utero and in the neonatal period influences the severity and chronicity of infection (Brabin et al, 2013).

Allowing normal placental transfusion can prevent hypovolaemia (Wyllie and Niermeyer, 2008). This is particularly relevant in the compromised baby. Hypovolaemia can lead to respiratory distress syndrome, and delayed cord clamping provides increased tissue oxygenation in first week of life (Johnson and Taylor, 2011). Delayed cord clamping provides 30\% extra blood volume (Van Rheenen, 2011), which is required to ensure effective transition to extra-uterine life as the cardiac output to the lungs increases from 10 to $40 \%$. It allows other organs to remain fully perfused alongside the increased pulmonary requirement (Mercer and Erikson-Owen, 2010). Red blood cells are required for oxygen transportation, and a deficit may cause problems with effective tissue function, maintaining $\mathrm{pH}$ and the circulatory integrity (Mercer and Erikson-Owen, 2010). Early cord clamping prematurely interrupts the respiratory function of the placenta in maintaining oxygen saturation for babies who are slow to breathe (McDonald, 2009).

Another important factor for the newborn is ? the increased transfusion of haematopoietic stem cells (HSCs), found to have substantial healing properties (Wasielewski et al, 2012). An early non-human study showed evidence to suggest that HSCs have the potential to aid recovery from brain injury caused by hypoxia (Rosenkranz et al, 2012), suggesting damage may be avoided or even reversed. Many newborn diseases relate to the immaturity of the organs, and stem cells play an essential role in the development of organs. Decreased HSCs may have long-term consequences leading to asthma, diabetes, epilepsy, Parkinson's disease and cerebral palsy (Tolosa et al, 2010).

\section{Benefits for preterm babies}

There may be further benefits of delayed cord clamping for the preterm baby (Fanaroff et al, 2011). Delaying clamping may lead to a decreased need for blood transfusion (Rabe et al, 2012). The risks of blood transfusions in the preterm baby are intraventricular haemorrhage with early transfusion, and necrotising enterocolitis if the transfusion occurs later (Christensen et al, 2013). Studies suggest delayed cord clamping in very-lowbirth-weight male babies has a protective factor against motor disability at 7 months corrected age (Mercer et al, 2010). Early clamping may harm the preterm baby with a compromised cardiovascular system, who may already be at risk of asphyxia, by causing hypovolaemia (Tonse and Raju, 2013). Delayed cord clamping can cause beneficial haemodynamic changes, with greater right ventricular output and stroke volume seen 48 hours later (Sommers et al, 2012). There is also increased blood flow in the superior vena cava (Meyer and Mildenhall, 2012), improved blood pressure and systemic vascular resistance, 
and better systemic and cerebral haemoglobin transport (Nelle et al, 2012). In very-low-birthweight babies, delayed cord clamping resulted in higher Apgar scores at 1 minute and fewer babies required resuscitative intervention (Kaempf et al, 2012). When the cord is clamped early, the umbilical arterial occlusion causes decreased right ventricular preload and at the same time increased left ventricular afterload. If the baby is not breathing or there is inadequate ventilation or respiratory distress, the pulmonary vascular resistance remains high causing inadequate pulmonary blood flow; therefore, reducing the oxygenated blood flow to the left side and causing a drop in left ventricular output. This may then mean that the caregiver needs to give a fluid bolus, creating a risk of intracranial haemorrhage (Tonse and Raju, 2013). Despite the evidence of the benefits and no significant adverse effects, only $24 \%$ of units in the UK practice delayed cord clamping in preterm babies (Singh and Oddie, 2012).

Delayed cord clamping is viewed as an intervention that needs to be trialled and proved (Mercer et al, 2008). Cowan et al (2003) found, using magnetic resonance imaging, that for only $1 \%$ of babies with hypoxic-ischaemic encephalopathy and seizures, the cause was in utero. They concluded that events immediately after birth are the most important factor in causing or avoiding harm. A low Apgar score at 5 minutes is strongly associated with cerebral palsy (Lie et al, 2010; Malin et al, 2013). Rozenkranz et al (2012) suggest that the cord haematopoietic stem cells may reverse damage caused by hypoxic-ischaemic brain injury; therefore, it may be beneficial for babies suffering from severe asphyxia at birth to receive delayed cord clamping.

Placental transfusion may play a role in reducing the use of drugs and volume expanders and assisting in avoiding hypovolaemia (Wyllie and Niermeyer, 2008). A bradycardia may be reversed and restore the blood pressure above the critical threshold, eradicating the need for adrenaline, for which there is no real evidence of efficacy (Resuscitation Council UK, 2010). Early cord clamping before the lungs are inflated causes reflex bradycardia as a response to cord occlusion (Niermeyer and Velaphi, 2013), in the same way that during labour a bradycardia may be seen with cord compression. Perhaps in the already compromised baby, clinicians are increasing the rate of compromise by their 'cut and run' approach.

\section{In case of resuscitation}

Many authors state resuscitation as a reason not to use delayed cord clamping (Strauss et al, 2008;
Wiberg et al, 2008; Resuscitation Council UK, 2010). But it is the non-breathing baby who needs placental transfusion the most. There is little evidence of the effectiveness of delayed clamping with a baby requiring extensive resuscitation, due to this normally being an exclusion criterion (Niermeyer and Velaphi, 2013). However, the principles indicate that it will be of most benefit to those individuals (Mercer et al, 2008). The practice of early cord clamping in a compromised baby to resuscitate away from the mother should be challenged if the placenta is seen as a resuscitative organ in this situation (Walsh, 2012). Weeks (2007) states that, while the cord blood continues to flow it is sending oxygenated blood back to the baby while respiration is being established.

Most newborns do not need extensive resuscitation. The initial stabilisation and inflation breaths can be carried out while the baby is still attached to the cord, providing extra oxygenated blood, preventing hypovolaemia and enabling effective tissue perfusion (Van Rheenen, 2011). Effective respiratory function is reduced with early cord clamping due to the abrupt halt of blood transfer (Walsh, 2012). The Resuscitation Council UK (2010) states that while there is not enough evidence to suggest a time for delaying cord clamping with a baby who requires resuscitation, perhaps this is because time should not be the defining parameter. Traditionally, the focus in a neonatal resuscitation has been on supplying oxygen through breath, but this discounts the normal physiological process driven by blood volume rather than oxygen, and then facilitating respiration (Mercer et al, 2008). Mercer and Skovgaard (2002) detail the blood volume model of neonatal transition, backed up by substantial evidence. While this is still a theory, no other model has been proposed which explains the relationship between oxygen transportation, red blood cell volume and the initiation of respiration (Figure 1). An understanding of this model may allow midwives to work more effectively to enhance neonatal transition to extra-uterine life.

There are some babies who would not require resuscitation if their physiological transition at birth had not been disturbed by early cord clamping (Niermeyer and Velaphi, 2013).

\section{Facillitation}

Historically there has been conflict between early cord clamping and successful resuscitation (Hutchon, 2014). There are many practical considerations to facilitate placental transfusion in a compromised baby. Immediate stabilisation can take place on the mother's abdomen, however, 
1. Fetal circulation: Lungs only receive $8 \%$ of fetal cardiac output $40 \%$ of $\mathrm{CO}$ goes to the placenta
2. Second stage of labour uterine contractions create pressures of $>80 \mathrm{mmHg}$ in the uterus, forcing additional blood from the placenta to the fetus immediately before and during birth
3. Increased pressure and blood volume force increased perfusion throughout the body and lungs

\section{Continuous respirations begin}

4A. Increased perfusion leads to capillary erection in pulmonary capillaries and increased $\mathrm{CO}$ to lungs
5A. Umbilical circulation continues to provide $\mathrm{O}_{2}$, volume expansion, $\mathrm{pH}$ correction

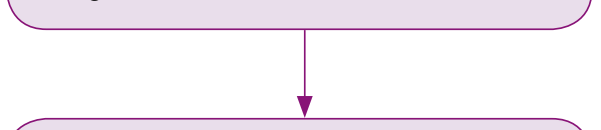

4B. Increased pulmonary perfusion pulls fluid from alveoli across capillary membrane

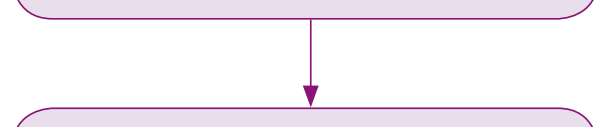

4C. CO to lungs greatly increased. Air enters the alveoli gently and without effort or with crying
5B. Increased whole body perfusion leads to elevated $\mathrm{O}_{2}$ levels
5C. Increased $\mathrm{O}_{2}$ levels lead to stimulation of the respiratory centre in the brain

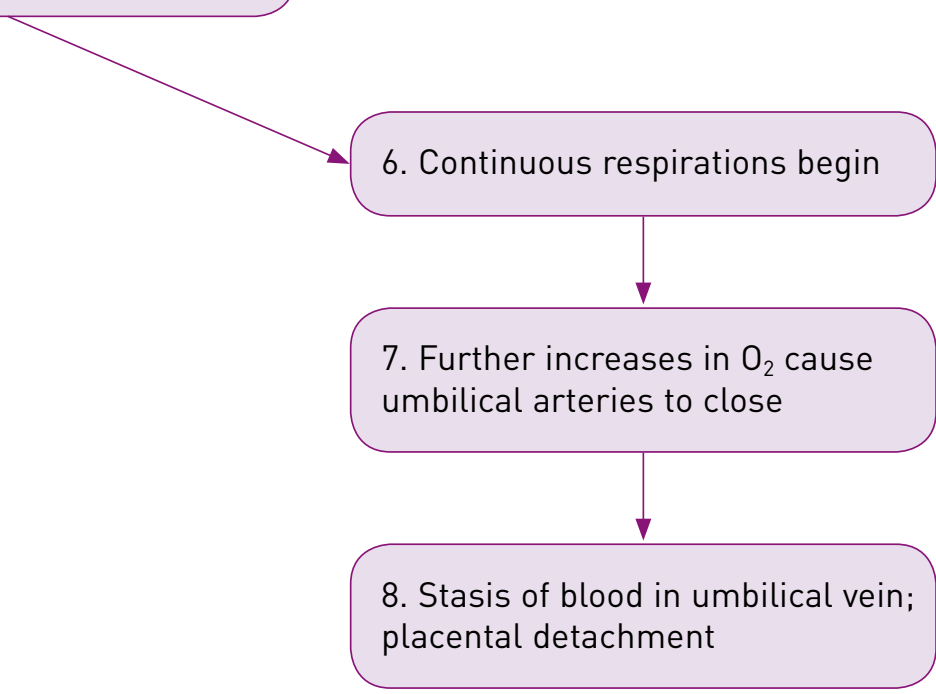

Figure 1. Blood volume model of neonatal transition (Mercer and Skovgaard, 2002)

further resuscitation requires a flat surface, and the baby may benefit from being lowered below the level of the placenta (Niermeyer and Velaphi, 2013). It is often possible to begin inflation breaths and ventilation breaths on the bed using a bag J and mask, ensuring that the surface is not wet and the baby is well wrapped to avoid hypothermia. A changing mat could be placed on the bed to avoid a wet surface. There is no heat source on the bed, as there would be on a Resuscitaire, so careful attention should be paid to guaranteeing the baby is warm. While avoiding hypothermia is an essential part of resuscitation, it need not be the cause of early cord clamping (Mercer et al, 2008). Hutchon (2008) states that common sense measures should be adequate to overcome issues surrounding heat loss.

Bedside resuscitation trolleys have been developed, allowing a work surface close to the mother so the cord can remain intact (Niermeyer 


\section{Key points}

Early cord clamping before initiation of respiration may create the need for resuscitative measures by causing a reflex bradycardia

Maintaining cord integrity allows the placenta to fulfil its respiratory function, providing a continued source of oxygen to a non-breathing baby

The prevention of hypovolaemia, achieved through delayed cord clamping is especially important for preterm babies

The increased volume from delayed cord clamping leads to decreased need for drug therapy and volume expanders, reversing bradycardia and restoring blood pressure

It is practical to initiate the first resuscitative measures while maintaining cord integrity
The relationship between the mother and the midwife holds great importance (Raynor and England, 2010). The midwife should be able to talk the woman through what is happening, empowering her as she calmly explains the value of the placental transfusion and the role the mother is playing in the resuscitation. The control is maintained by the woman as she realises she is providing a source of oxygen to her baby before it takes its first breath. All resuscitative measures should be fully explained.

These points highlight the importance of clear communication with the woman, and the need for the midwife to be able to support her. Wherever possible, additional help should be called to the room not just for the resuscitation process but as support for the parents.

Velaphi, 2013). The Bedside Assessme Stabilisation and Initial Cardiorespiratory Support (BASICS) trolley can be lowered between the woman's legs or over an operating table and provides heat, suction and ventilation (Weeks et al, 2014). When trialled, the trolley was able to be successfully used for resuscitation and cord integrity was maintained in most cases (Thomas et al, 2014). Neonatal temperature was maintained and practitioners reported better communication with parents, while parents gave positive feedback. With earlier solutions not being acceptable to neonatologists due to lack of heat and positive end-expiratory pressure (PEEP), the BASICS trolley offers a practical resolution to the problem, satisfactory to practitioners (Hutchon, 2014).

\section{Psychological considerations}

An area of concern when thinking about the practicalities of delayed cord clamping in a compromised baby, was how the mother would cope. Knowing that the baby is in need of resuscitation is an obvious stress factor for both the mother and others present. There is very little literature about the specific psychological implications for the mother when resuscitation takes place with the cord attached. However, the presence of relatives at the resuscitation of a close family member has been shown not to be psychologically harmful, but to have benefits, with decreased rates of anxiety, depression and posttraumatic stress disorder seen in these relatives (Jabre et al, 2013). Family members stated that they gained a better understanding of the treatment and resuscitative efforts of the staff by being present (Pasquale et al, 2010). Porter et al (2013) reviewed 14 papers on the subject of family presence in the resuscitation room and concluded the psychological benefits outweigh the disadvantages, but more teaching is needed for emergency staff.

\section{Recommendations for practice}

The Code (Nursing and Midwifery Council (NMC), 2008) states that it is a professional responsibility to ensure knowledge and skills are kept up-todate, delivering care based on the best available evidence. Where new evidence and new technologies are available, the professionals should consider their application in practice.

Multidisciplinary training is essential and any change to current practice should be a team effort and education should be provided for all members of the team. Hutchon (2008) states that change should be led by paediatricians, and heeded by obstetricians. It is, after all, the paediatrician's patients who will most benefit. It is essential for midwives to possess a thorough understanding of the physiology. Midwives must know the physiology of neonatal transition to extra-uterine life, with an understanding of the blood volume model of neonatal transition. Contrary to past teaching, midwives should have a full understanding that an active management of the third stage does not need to involve early cord clamping (McDonald and Middleton, 2009). There must be an appreciation of the benefits of delayed cord clamping for almost every organ system in the baby (Niermeyer and Velaphi, 2013).

Effective teamwork is a vital part of midwifery (NMC, 2008), and multidisciplinary drills-andskills training specifically focused on resuscitating at the perineum could be a resource for improving confidence in professionals. This would help overcome the challenges midwives face in maintaining cord integrity during resuscitation in the hospital environment. The purchase of portable resuscitation trolleys may facilitate this. They will allow all the benefits of placental transfusion for the baby, while allowing medical 
staff to resuscitate in the way they have been trained, and helping to avoid hypothermia with a heated mattress. These changes are cost-effective. Serious complications, both long- and short-term, may be avoided in the baby, saving time and money in terms of neonatal intensive care, and care into the future. The idea that stem cells could reverse the effects of cerebral palsy following a hypoxic-ischaemic event could mean that millions of pounds are saved in compensation to affected families. Most importantly, the children affected could grow up with a better quality of life.

As is often the case when trying to answer clinical questions, further research is required. There need to be randomised controlled trials which look at both long- and short-term outcomes of delayed cord clamping including mortality, cerebral palsy and behavioural problems (Niermeyer and Velaphi, 2013). Further research must be conducted into cord-milking and the effectiveness of this in order to provide clear guidelines. The psychological effects for the mother and birth supporters should be studied, perhaps in a qualitative design using interviews to gain understanding of how the woman was affected.

\section{Conclusion}

The implications for practice are significant, and there is a realistic expectation that the physical barriers could be overcome, but will require reorganisation of equipment, and new training for staff (Niermeyer and Velaphi, 2013).

The important question is not is delayed cord clamping beneficial?', but 'is early cord clamping harmful?' The evidence suggests that it does cause harm, triggering hypovolaemia, anaemia (Hutchon, 2008) and reflex bradycardia in the baby (Niermeyer and Velaphi, 2013). As practitioners, we may be forced, by our duty of care, to move out of our comfort zone at the Resuscitaire, so as not to cause further compromise to the non-breathing baby. Let us not choose technology over physiology. With the further development of resuscitation equipment it may be that we do not have to choose in the future. In the meantime, as midwives we must act in the best interests of our clients using the evidence available.

Airey R, Farrar D, Duley L (2008) Timing of umbilical cord clamping: midwives' views and practice. British Journal of Midwifery 16(4): 236-9

Brabin L, Brabin B, Gies S (2013) Influence of iron status on risk of maternal or neonatal infection and on neonatal mortality with an emphasis on developing countries. Nutrition Reviews 71(8): 528-40

Castle N (2009) Neonatal and maternal resuscitation. In:
Chapman V, Charles C (eds) The midwife's labour and birth handbook, 2nd edn, Wiley-Blackwell, Chichester Christensen R, Baer V, Vecchio A and Henry E (2013) Unique risks of red blood cell transfusions in verylow-birth-weight neonates: associations between early transfusion and intraventricular haemorrhage and between late transfusion and necrotizing enterocolitis. J Matern Fetal Neonatal Med 26(S2): 6o-3. doi:10.3109/1 4767058.2013.830495

Cowan F, Rutherford M, Groenendaal F et al (2003) Origin and timing of brain legions in term infants with neonatal encephalopathy. Lancet 361(9359): 736-42

Darwin E (1801) Zoonomia. London

Fanaroff W, Carlo W, Donavan E, McDonald S, Poole W (2011) The effect of delayed cord clamping in very-lowbirth-weight infants. J Perinatol 31(Suppl 1): S68-71. doi:10.1038/jp.2010.186

Hutchon D (2008) Views and counter views, A view on why immediate cord clamping must cease in routine obstetric delivery. Obstet Gynecol 1o(2): 112-6

Hutchon D (2014) Evolution of neonatal resuscitation with intact placental circulation. Infant 1o(2): 58-61

Hutton E, Hassan E (2007) Late vs early clamping of the umbilical cord in full-term neonates; systematic review and meta-analysis of controlled trials. JAMA 297(11): 1241-52 doi:10.1001/jama.297.11.1241.

Jabre P, Belpomme V, Azoulay E et al (2013) Family presence during cardiopulmonary resuscitation. $N$ Engl J Med 368(11): 1008-18. doi: 10.1056/ NEJMoa1203366

Johnson R, Taylor W (2011) Skills for Midwifery Practice, 3rd edn. Churchill Livingstone Elsevier, London

Kaempf J, Tomlinson M, Kaempf A, Wu Y, Wang L, Tipping N, Grunkemeier G (2012) Delayed umbilical cord clamping in premature neonates. Obstet Gynecol 120(2): 325-30 doi:10.1097/AOG.obo13e31825f269f

Lie K, Grøholt E, Eskild A (2010) Association of cerebral palsy with Apgar score in low and normal birthweight infants: population based cohort study. BMJ 341: c499o. doi: 10.1136/bmj.c499o

Lozoff B, Beard J, Connor J, Felt B, Georgieff M, Schallert $\mathrm{T}$ (2006) Long-lasting neural and behavioral effects of iron deficiency in infancy. Nutr Rev 64(5 Pt2): S34-43. doi: 10.1111/j.1753-4887.2006.tboo243.x

Lozoff B, Georgieff M (2006) Iron deficiency and brain development. Semin Pediatr Neurol 13(3): 158-65

Malin G, Morris R, Ahmad S, Riley R, Khan K (2013) Does the Apgar score matter? Investigating the relationship between a low score and adverse outcomes from birth to childhood. Arch Dis Child Fetal Neonatal Ed 98(1): A83. doi:10.1136/archdischild-2013-303966.285

McDonald S (2009) Physiology and management of the third stage of labour. In: Fraser and Cooper, Myles Textbook for Midwives. 15th edn. Churchill Livingstone Elsevier, London

McDonald SJ, Middleton P (2008) Effect of timing of umbilical cord clamping of term infants on maternal and neonatal outcomes. Cochrane Database Syst Rev 2 (2):CDoo4074. doi: 10.1002/14651858.CDoo4074.pub2.

Mercer J, Erikson-Owens D (2010) Evidence for neonatal transition and the first hour of life. In: Walsh D, Downe S, Essential Midwifery Practice; Intrapartum Care, Wiley-Blackwell, Chichester

Mercer J, Skovgaard R (2002) Neonatal Transitional 
Physiology; A new paradigm. J Perinat Neonatal Nurs 15(4): 56-75

Mercer J, Skovgaard R, Erikson-Owens D (2008) Fetal to neonatal transition: first do no harm. In: Downe S, Normal Childbirth; Evidence and debate. 2nd edn. Churchill Livingstone Elsevier, London

Mercer J, Vohr B, Erikson-Owens D, Padbury J and Oh W (2010) Seven-month developmental outcomes of very low birth weight infants enrolled in a randomized controlled trial of delayed versus immediate cord clamping. J Perinatol 3o(1): 11-16 doi:10.1038/ jp.2009.170

Meyer M, Mildenhall L (2012) Delayed cord clamping and blood flow in the superior vena cava in preterm infants: an observational study. Arch Dis Child Fetal Neonatal Ed 97(6): F484-6. doi:10.1136/adc.2010.199703

National Institute for Health and Care Excellence (2014) Intrapartum Care: Care of healthy women and their babies during childbirth. NICE, London

Nelle M, Walter K, Gerull R (2012) Late cord clamping improves circulation in neonates. Arch Dis Child $\mathbf{9 7}(\mathbf{2})$ : A6. doi:10.1136/archdischild-2012-302724.0019

Niermeyer S, Velaphi S (2013) Promoting physiologic transition at birth: Re-examining resuscitation and the timing of cord clamping. Semin Fetal Neonatal Med 18(6): 385-92. doi: 10.1016/j.siny.2013.08.008

Nursing and Midwifery Council (2008) The Code. NMC, London

Pasquale MA, Pasquale MD, Baga L et al (2010) Family Presence during trauma resuscitation: Ready for Primetime? J Trauma 69(5): 1092-100

Porter J, Cooper S, Sellick K (2013) Attitudes, implementation and practice of family presence during resuscitation (FPDR): A quantitative literature review. Int Emerg Nurs 21(1): 26-34

Rabe H, Diaz-Rossello JL, Duley L, Dowswell T (2012) Effect of timing of umbilical cord clamping and other strategies to influence placental transfusion at preterm birth on maternal and baby outcomes. Cochrane Database Syst Rev 8: CDoo3248. doi: 10.1002/14651858. CDoo3248.pub3

Raynor M, England C (2010) Psychology for Midwives. Open University Press, Maidenhead

Resuscitation Council UK (2010) Newborn Life Support' Resuscitation Guidelines. http://www.resus.org.uk/ pages/nls.pdf (accessed 14 January 2015)

Rosenkranz K, Kumbruch S, Tenbusch M, Marcus K, Marschner K, Dermietzel R, Meier C (2012) Transplantation of human umbilical cord blood cells mediated beneficial effects on apoptosis, angiogenesis and neuronal survival after hypoxic-ischemic brain injury in rats. Cell Tissue Res 348(3): 429-38

Royal College of Midwives (2012) Evidence based guidelines for midwifery-led care in labour. https://www.rcm.org. uk/sites/default/files/Supporting\%2oWomen\%2oin\%2o Labour_1.pdf (accessed 14 January 2015)

Singh Y, Oddie S (2012) Delayed cord clamping in preterm babies (<32 weeks gestation): Current clinical practice in the United Kingdom. Arch Dis Child 97(2): A6-7. doi:10.1136/archdischild-2012-302724.0021

Sommers R, Stonestreet B, Oh W, Laptook A, Yanowitz TD, Raker C, Mercer J (2012) Hemodynamic effects of delayed cord clamping in premature infants. Paediatrics 129(3): E667-672

Strauss R, Mock D, Johnson K, Cress G, Zimmerman M, Bell E, Rijhsinghani A (2008) A randomized clinical trial comparing immediate versus delayed clamping of the umbilical cord in preterm babies: short-term clinical and laboratory endpoints. Transfusion 48(4): 658-65

Thomas M, Yoxall C, Weeks A, Duley L (2014) Providing newborn resuscitation at the mother's bedside: assessing the safety, usability and acceptability of a mobile trolley. BMC Pediatrics 14(135): doi: 10.1186/1471-2431-14-135

Tolosa J, Park D, Eve D, Klasko S, Borlongan C, Sanberg P (2010) Mankind's first natural stem cell transplant. J Cell Mol Med 14(3): 488-95. doi: 10.1111/j.1582-4934.2010.01029.x

Tonse N, Raju M (2013) Don't rush to cut the cord; new recommendations call for delayed cord clamping in preterm infants. American Academy of Paediatrics News 34(4): 17 doi: 10.154/aapnews.2013344-17

Van Rheenen (2011) delayed cord clamping and improved baby outcomes. BMJ 343:d7127. doi:10.1136/bmj.d7157

Walsh D (2012) Evidence And Skills For Normal Labour And Birth: A Guide For Midwives. 2nd edn, Routledge, Oxen

Wasielewski B, Jensen A, Roth-Härer A, Dermietzel $R$, Meier C (2012) Neuroglial activation and $C_{4} 43$ expression are reduced upon transplantation of human umbilical cord blood cells after perinatal hypoxicischemic injury. Brain Res 1478: 39-53

Weckert R, Hancock H (2008) The importance of delayed cord clamping for Aboriginal babies: A life-enhancing advantage. Women and Birth 22(1): 41

Weeks A, Watt R, Hutchon D, Yoxall C, Gallagher A, Burleigh A, Bewley S, Heuchan A, Duley L (2014) Innovation in immediate neonatal care: development of the Bedside Assessments, Stabilisation and Initial Cardiorespiratory Support (BASICS) Trolley. www. nottingham.ac.uk/nctu/documents/preterm-birth/ basics-development-report-29april2014.pdf (accessed 15 January 2015)

Weeks A (2007) Umbilical cord clamping after birth. BMJ 335(7615): 312-3 doi: 10.1136/bmj.39282.440787.8o

Wiberg N, Kallen K, Olofsson P (2008) Delayed umbilical cord clamping at birth has effects on arterial and venous blood gasses and lactate concentrations. BJOG 115(6): 697-703

World Health Organization (2012) Guidelines on basic newborn resuscitation. WHO, Geneva

Wyllie J, Niermeyer S (2008) The role of resuscitation drugs and placental transfusion in the delivery room management of newborn babies. Semin Fetal Neonatal Med 13(6): 416-23 